\title{
Fluxo enxuto de informação: um novo conceito
}

\section{Ana Carolina Greef}

\begin{abstract}
Pesquisadora em Fluxos de Informação, Gestão da Informação e Mentalidade Enxuta, com projeto de investigação em gerenciamento e avaliação de Fluxos de Informação em sistemas de Gestão de Processos de Negócio
\end{abstract}

Maria do Carmo Duarte Freitas

\begin{abstract}
Investigadora do Grupo de Pesquisa em Ciência, Informação e Tecnologia na UFPR, com projetos de pesquisa em processos de geração, disseminação de inovações tecnológicas nas atividades de produção de bens e serviços de informação
\end{abstract}

A informação representa um valor que, entregue em conformidade às demandas de seus usuários/clientes, gera inovação, inteligência e competitividade. Os conceitos de qualidade da informação, aplicados ao seu fluxo, quando gerenciado pelas organizações, agilizam processos decisórios. A mentalidade enxuta (lean thinking), aplicada em ambientes organizacionais, identifica o valor esperado pelos mesmos clientes/usuários e incentiva a geração de padrões em processos produtivos, a eliminação de falhas e a melhoria contínua. Este artigo resulta de pesquisa exploratória e bibliográfica, com objetivo de oferecer parâmetros para qualificação da gestão e da operação de fluxos informacionais, com base em critérios oriundos do lean thinking. Para tanto, apresenta um conceito de Fluxo Enxuto de Informação (FEI), concebido e analisado criticamente diante do referencial teórico em Ciência da Informação e mentalidade enxuta. Novos elementos teóricos, de uso potencial pelo profissional da informação, são oriundos da pesquisa, cuja contribuição incentiva discussões cientificas sobre aplicações de ambas as áreas à gestão organizacional, no que tange à avaliação de fluxos informacionais.

Palavras-chave: Fluxo enxuto de informação; Critérios de qualidade; Mentalidade enxuta; Avaliação de fluxo de informação. 


\section{Lean information flow: a new concept}

Information represents a value delivered in accordance to demands of its customers generating innovation, competitiveness and intelligence. The quality of information flow managed in organizations makes their decision-making processes easier. When applied in organizations lean thinking identifies the expected value of customers, creates patterns in manufacturing processes, eliminates failures and improves processes continuously. This article results from exploratory research which provides parameters for qualification of the management and the operation of information flows, that are based on criteria derived from the lean thinking. It presents a concept of Lean Information Flow, designed and analyzed according to the theoretical framework in Information Science and lean thinking. The research brings about new theoretical elements of potential use by information professionals and presents as contribution a scientific basis for discussions regarding the evaluation of information flow.

.Keywords: Lean Information flow; Quality criteria; Lean thinking; Information flow evaluation.

Recebido em 20.03.2011 Aceito em 25.01.2012

\section{Introdução}

A partir da década de 1990, no Brasil, mercados passaram a atender exigências de customização de produtos/serviços por parte dos clientes e a concorrer globalmente. Formou-se um fluxo informacional crescentemente intenso em organizações, classificado por Wurman (2005) e Mattos (2010), respectivamente, como ansiedade e avalanche de informação, cujas demandas já não eram facilmente atendidas pelos meios disponíveis.

Sordi (2008) afirma que o valor das informações, nesse contexto, precisa estar explícito e traduzido em fatores, como relevância, utilidade, clareza, objetividade, contextualização. Mattos (2010) alerta que deficiências quanto aos mesmos geram novas demandas, conteúdos e comunicações desnecessários, cujo tempo de produção diminui aquele disponível para solução de outros problemas.

Hicks (2007) observa que gerir informações e aperfeiçoá-las constantemente, em organizações, beneficia operações de todas as áreas e agrega a elas eficiência, competitividade e responsabilidade. Nesse 
sentido, a qualidade do desempenho organizacional é relacionada a dos fluxos de recursos que perpassam o contexto: quando aderentes $e$ sinérgicos ao ambiente em questão, contribuem para o alcance de objetivos operacionais, táticos e estratégicos (FARIAS, 2007). Para tanto, cabe à Gestão da Informação desenvolver soluções criativas e de custobenefício correspondente ao investimento disponibilizado por seus usuários; planejar políticas de uso e manutenção destas; e organizar e aprimorar fluxos informacionais.

O caráter estratégico da informação exige dos ambientes em que está inserida a postura de aperfeiçoar processos internos, para que demandas de usuários sejam atendidas em plenitude. A manutenção do valor gerado nesse processo representa uma premissa da mentalidade enxuta, junto à identificação de onde é gerado em fluxos produtivos, ao aprimoramento de processos para sua entrega aos clientes/usuários e à eliminação de atividades que geram desperdícios (WOMACK; JONES, 2003).

Roedel (2006) sugere o aperfeiçoamento como resposta a duas questões: quanta informação se perde devido a ruídos da comunicação e quanto conhecimento é perdido por causa da primeira. Em complemento, Hicks (2007) sugere que a mentalidade enxuta oferece à gestão de fluxo informacional, soluções centradas na melhoria constante e na agregação de valor.

Inexiste correspondência explícita entre a mentalidade enxuta e a Gestão da Informação e, especialmente quanto à gestão e avaliação de fluxos informacionais, a mesma é explorada de forma incipiente na literatura do Século XXI. Partindo do pressuposto de que o lean thinking representa um aliado em potencial ao tema, relata-se, neste artigo, a investigação a respeito das características que qualificam como enxutos (lean) os fluxos de informação.

\section{Fluxo de informação: definições}

Como produto ou como insumo, a informação precisa fluir ininterruptamente pelo ambiente em que se encontra (MACHADO; TOLEDO, 2008), impulsionando seu desenvolvimento interno e externo quando adquirida, tratada, interpretada e utilizada estrategicamente, com postura inovadora (MCGEE; PRUSAK, 1994).

Fluxo, em essência, representa a série de tarefas inerentes ao desenvolvimento e à comunicação de determinado produto/serviço, permeando a organização e ciclos contínuos de avaliação (MACHADO; TOLEDO, 2008). Jamil (2001, p. 165) denomina fluxo informacional "a transmissão de dados ou conjunto de dados através de unidades administrativas [...], organizações e profissionais, [...] para alguém que delas necessitam", cujo caminho é diversificado e sem limites.

Compreender a conjuntura dos fluxos de informação depende de delinear seu conceito: sequência de eventos desde a geração da 
informação, por parte do emissor, até sua captação/assimilação/aceitação pelo receptor, gerando saberes individuais e coletivos (BARRETO, 1998); elemento integrador de cadeias produtivas que, se precário, origina falhas (JACOSKI, 2005); processo disseminador de informações que media a comunicação (ALTÍSSIMO, 2009). As definições culminam nos elementos citados por Barreto (1998) e Altíssimo (2009): subsídio à tomada de decisão, viabilização de diagnósticos de demandas e oportunidades de melhoria.

Apesar dos benefícios citados pela literatura, nos ambientes em que se encontram, fluxos de informação são vulneráveis à geração de adversidades diretas e indiretas (OLIVEIRA, 2002). Na medida em que ocorrem e que a atividade correspondente ao problema não culmina na geração de conhecimento, observam-se condições, como:

a) redundância da informação e consequente aumento de custo de desenvolvimento e/ou inserção da mesma em veículos de comunicação; inconsistência de informações obtidas de fontes diversas; fragmentação da informação comunicada entre setores da organização (BEAL, 2008);

b) barreiras de comunicação, diminuindo sua eficiência, por parte tanto do emissor (esforços para cumprir seu papel) quanto do usuário (esforços para real utilização da informação); Dificuldade em aceitar riscos associados a novas formas de fazer fluir a informação no ambiente; Tentativas de aumentar o fluxo de informação que prejudicam sua objetividade ideal (FREIRE, 2006);

c) desorganização do fluxo e decorrente ineficiência (LE COADIC, 1996 apud ALTISSIMO, 2009); e

d) informação desqualificada e desordenada; má distribuição das tarefas entre colaboradores (CANOVA; PICCHI, 2009).

Essas condições comprometem o desempenho e o alcance de objetivos no âmbito organizacional, por meio da informação, pois: aumentam custos de operação, dificultam a comunicação e a interação entre indivíduos e departamentos, prejudicam a compreensão do papel estratégico da informação e de atividades correlatas. Para evitar tais adversidades, faz-se necessário diagnosticar o estado atual dos fluxos informacionais em questão.

\section{Diagnóstico e representação}

O diagnóstico de fluxos informacionais é essencial para o reconhecimento de sua eficiência, de gargalos decorrentes da falta desta e para sua adequação à necessidade dos interessados (JACOSKI, 2005). Oliveira (2002) apresenta o fluxograma como principal veículo de sua tradução em uma sequência visível de ações, que representa gráfica, racional, clara e logicamente: rotinas e procedimentos ligados à tramitação de documentos, insumos de entrada, processamentos e 
recursos de saída, emitentes e receptores envolvidos. A representação tem como objetivos, conforme o autor (OLIVEIRA, 2002, p. 257):

a) padronizar a representação de métodos e processos administrativos;

b) agilizar a descrição, leitura e entendimento dos mesmos;

c) viabilizar a identificação rápida de prioridades;

d) possibilitar diferentes graus de análise dos métodos e processos; e

e) evidenciar falhas e deficiências no processo retratado.

Além de representar uma fotografia do estado corrente do processo, o fluxograma agiliza o desenvolvimento de soluções para desperdícios ali desenhados, conforme Machado e Toledo (2008). Torna-se possível, portanto, eliminar etapas supérfluas no fluxo, associar aquelas de natureza similar e diminuir o percurso de informações e demais recursos.

A transparência na sistematização do fluxo informacional em seu ambiente nativo viabiliza uma gestão presente e lúcida do mesmo, baseada em conhecimento, no dimensionamento de recursos e na comunicação por mídias ideais (JAMIL, 2001).

\section{Gestão e qualidade do fluxo de informação}

A gestão citada por Jamil (2001), é classificada por Sant'ana e Santos (2004) como fonte de sobrevivência, diante da necessidade de controlar, incrementar e utilizar competitivamente a informação, no que tange à eficiência em processos, à acessibilidade de insumos para o conhecimento e à capacidade de interpretá-los.

Logo é característica do fluxo de informação o fornecimento aos seus interessados, de ativos valiosos à tomada de decisão com suas devidas oportunidades, temporalidade, estrutura e suficiência (VAITSMAN, 2001). O estabelecimento desse cenário depende da postura dos níveis organizacionais, visto que, conforme Jamil (2001), são responsáveis por operacionalizar as ações de:

a) criação/geração da informação que deverá ser utilizada;

b) armazenamento/guarda da informação a ser transferida no fluxo;

c) definição da informação tramitada com peculiaridades da demanda;

d) processamento/recepção da informação comunicada via fluxo, sendo facultativa a sequência lógica de interpretação e 
de armazenamento da informação, descartada se contrária à demanda;

e) distribuição efetiva do fluxo informacional;

f) segurança quanto a acesso/reprodução do conteúdo do fluxo;

g) testes e auditoria quanto à qualidade da informação; e destruição devido à quebra de sigilo.

Essas atividades são facilitadas por meio de fatores ambientais, como os citados por McGee e Prusak (1994) e Roedel (2006):

a) contar com a participação de todos os interessados;

b) criar políticas que transpareçam o interesse da alta gerência e o tornem acessível e praticável pelos demais níveis da organização;

c) oferecer respaldo ao seu fluxo na própria cultura organizacional, tornando acessível e estimulando sua comunicação;

d) definir os campos de interesse por informações;

e) definir aquelas mantidas internamente e adquiridas de fontes externas;

f) identificar estratégias para estabelecimento de suas origens;

g) eliminar o ruído a ela inerente;

h) eliminar informação indesejada e desnecessária;

i) aperfeiçoar sua adaptabilidade às demandas existentes; e

j) aprimorar modelos para seu compartilhamento.

Cabe observar o valor da informação inerente a esses fatores, quando Farias (2007) ressalta a necessidade de qualificá-la conforme critérios que representam um estado ideal de fluxo. Desse modo, evitamse erros e prejuízos operacionais, bem como decisões incorretas no ambiente em questão. Os principais critérios para tanto, listados pela literatura, são sumarizados no Quadro 1:

Quadro 1 - Critérios de qualidade da informação

\begin{tabular}{l|l}
\hline \multicolumn{1}{c|}{ Critério } & \multicolumn{1}{c}{ Definição } \\
\hline Abrangência / Escopo & Capacidade, da informação, de ser suficiente para solucionar o problema \\
\hline Acurácia / Veracidade & Caráter legítimo e verdadeiro da informação, passíveis de verificação \\
\hline Confiabilidade & Grau em que a informação torna-se justificável e passível de conferência \\
\hline Confidencialidade / & $\begin{array}{l}\text { Manutenção do sigilo de informações de caráter particular e/ou } \\
\text { estratégico, associada à confiança quanto ao compartilhamento }\end{array}$ \\
\hline Privacidade & União dos estados tácito e explícito da informação \\
\hline Existência & $\begin{array}{l}\text { Características da informação que a tornam atrativa e agregam } \\
\text { significado a ela, em relação a seu público-alvo }\end{array}$ \\
\hline Contextualização & Nomenclatura e rotulação da informação para que seja identificada \\
\hline Identidade
\end{tabular}




\begin{tabular}{l|l}
\hline \multicolumn{1}{c|}{ Critério } & \multicolumn{1}{c}{ Definição } \\
\hline Ineditismo / Raridade & $\begin{array}{l}\text { Grau em que a informação é rara, não percebida ou disponibilizada como } \\
\text { estratégica no ambiente em que se encontra }\end{array}$ \\
\hline Originalidade & Medida em que a informação é gerada pela primeira vez \\
\hline Pertinência / & $\begin{array}{l}\text { Medida em que a informação atende demandas e decisões a serem } \\
\text { tomadas, e contribui de forma especial para as mesmas }\end{array}$ \\
\hline Agregação de valor & Grau em que a informação é acessada e permanece de interesse \\
\hline Audiência & Informação que reflete a necessidade \\
\hline Amplitude & Alcance e foco da informação, no ambiente interno e/ou externo \\
\hline Apresentação / Mídia & Formato e mídia utilizados para apresentar e/ou apresentar a informação \\
\hline Clareza & Grau de facilidade de compreensão da informação \\
\hline Concisão & $\begin{array}{l}\text { Apresentação somente da informação necessária para o problema ou } \\
\text { situação em questão }\end{array}$ \\
\hline Desempenho & Relatividade da informação ao desempenho do ambiente \\
\hline Detalhamento & Grau de minúcia contido na informação de que se trata \\
\hline Frequência (de uso) & Capacidade da informação de ser utilizada várias vezes \\
\hline Ordem & Organização da informação conforme um esquema predefinido \\
\hline Relevância & Coerência/Coesão da informação em relação ao problema \\
\hline Precisão & Informação livre de erros \\
\hline Integridade & Informação incorruptível \\
\hline Atualidade / Período / & $\begin{array}{l}\text { Vínculo da informação com a realidade em que se insere; sua capacidade } \\
\text { de refletir estados anterior, atual e futuro do ambiente }\end{array}$ \\
\hline Temporalidade & $\begin{array}{l}\text { Informação disponível àqueles que dela necessitam, no momento ideal } \\
\text { para atender à demanda }\end{array}$ \\
\hline Disponibilidade / \\
Prontidão
\end{tabular}

Fonte: Adaptado de Silva (2003); Sordi (2008).

A qualidade da informação em fluxo deriva da compreensão, do controle, da verificação e da manutenção dos critérios apresentados no Quadro 2, em quaisquer ambientes, quando aplicados em conformidade ao ciclo de vida da informação e aos fatores facilitadores apontados por McGee e Prusak (1994) e Roedel (2006). Segundo Silva (2003), o investimento e a manutenção da qualidade, como parte da cultura organizacional, asseguram validade e utilidade dos dados, informações e conhecimentos inerentes ao mesmo contexto.

\section{Mentalidade enxuta (lean thinking)}

Oriundo da gestão da produção e do sistema Toyota de organização industrial, o conceito "enxuto" foi apresentado à comunidade científica em 1990, em obra de James Womack e Daniel Jones. A proposta transformou o processo produtivo em um fluxo de atividades transformadoras e não transformadoras, sobrepondo a tradicional conversão de insumos em produtos (ROCHA et al., 2004).

A mentalidade enxuta (lean thinking) foi concebida em 1996, decorrente do novo paradigma industrial e como norte para modelos de negócio, sendo que:

Provê um meio de especificar valor, sequenciar de maneira otimizada as ações de geração de valor, conduzi-las sem interrupção quando são requisitadas e realizá-las com crescente efetividade. Em suma, o lean thinking [...subsidia...] a realização de cada vez mais, com cada vez menos. (WOMACK; JONES, 2003, p. 15, tradução nossa). 
Cinco princípios norteiam a concepção plena da mentalidade enxuta, a partir do conceito de Womack e Jones:

a) valor: definido pelo cliente/usuário final em forma de um produto ou serviço específico que atende e soluciona a demanda ou problema. E contrário ao desperdício, sintoma de problemas no ambiente produtivo, cujas causas devem ser averiguadas e tratadas (PICCHI, 2001; WOMACK; JONES, 2003, tradução nossa);

b) cadeia de valor: conjunto de ações requeridas para "mover" um bem/serviço em processos de resolução de problemas, gestão da informação e transformação física em produto. A análise da cadeia composta por essas ações evidencia atividades que efetivamente geram valor, não geram valor e são inevitáveis, não geram valor e precisam ser imediatamente eliminadas (WOMACK; JONES, 2003, tradução nossa);

c) fluxo: refere-se ao caráter constante assumido pelo processo produtivo, exigindo tanto o seu controle quanto a estruturação do modelo mental associado (WOMACK; JONES, 2003, tradução nossa). Integra design, pedido e produto em um único ciclo contínuo, de modo a eliminar custos, maximizar a expectativa e sua resposta (PICCHI, 2001);

d) "puxar": realização das tarefas de produção apenas mediante apresentação da demanda pelo produto/serviço por parte do cliente (PICCHI, 2001); e

perfeição: busca contínua da aproximação entre o bem/serviço criado e a necessidade do mercado. A agilidade no mapeamento de problemas e sua solução, também em níveis de baixa hierarquia, são citadas por Picchi (2001), como exemplos de elementos inerentes à perfeição na mentalidade enxuta.

\section{Gestão lean}

Neste início de século XXI, a gestão organizacional requer visão sistêmica, relacionamento de informações de diversas origens para tomada de decisão, qualidade de produtos/processos e gestão de colaboradores. O desafio de torná-la enxuta extrapola os princípios base do lean, utilizando-se daqueles relacionados ao planejamento e ao controle de recursos operacionais (da produção) e gerenciais (pessoas e informações). Todos estes itens geram um contexto para a gestão lean, devidamente de acordo à cultura da mentalidade enxuta.

O Quadro 2 sintetiza as quatorze premissas de Liker (2005) para uma gestão enxuta, categorizadas quanto à relação com gestão da 
qualidade (GQ), gestão da produção (GP), gestão de pessoas (GPe), gestão da informação (GI), tomada de decisão (TD) - temas a serem administrados; e relacionadas aos princípios do lean thinking - valor (V), cadeia de valor $(C V)$, fluxo $(F)$, produção puxada $(P P)$ e perfeição $(P)$. Dependências mútuas entre o gerenciamento na mentalidade enxuta e a implementação desta última são observáveis nas interseções, respectivamente, entre linhas e colunas do Quadro 2:

Quadro 2 - Princípios lean e de gestão

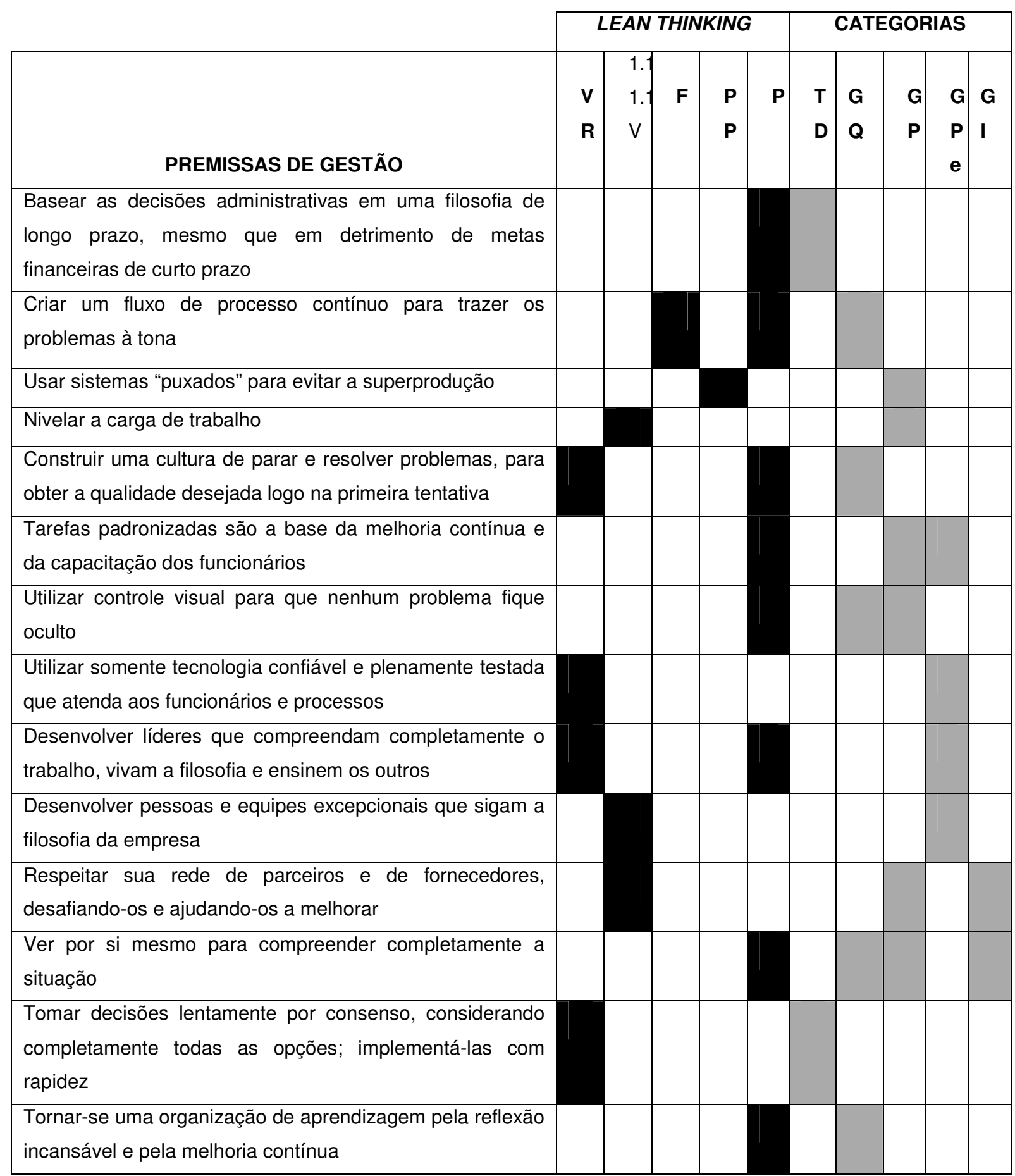

Fonte: adaptado de Womack e Jones (2003); Liker (2005). 
No primeiro item do Quadro, lê-se que decisões administrativas são baseadas no longo prazo, fator relacionado à perfeição e à tomada de decisão, em essência. A leitura sucessiva dos demais itens esclarece como um ambiente é gerenciado de maneira enxuta e permite concluir que a filosofia lean interfere além da produção em contextos de indústria, comércio e serviços. Logo, deve representar um elemento cultural, que parte do comprometimento da alta administração e da sensibilização dos demais interessados, enquanto influenciadores do sucesso da iniciativa no ambiente organizacional (LIKER, 2005).

Como decorrência, fluxos enxutos de produção são planejados para minimizar desperdícios, inclusive de tempo na tomada de decisão. Observando-se as correlações existentes no Quadro, nota-se que a informação - insumo direto nesse processo decisório, até então, permanece dissociada da maioria das características lean. Acredita-se que tal cenário se deve à ausência de conceitos e elementos claros de interseção entre informação e mentalidade enxuta.

\section{Procedimentos metodológicos}

Este artigo relata os resultados de uma pesquisa de caráter exploratório, por desenvolver e transformar conceitos e aplicar a comparação entre teorias (GIL, 2009), que se propôs a oferecer parâmetros para qualificação de fluxos de informação, com apoio em critérios oriundos da mentalidade enxuta.

A proposta partiu da investigação do que poderia caracterizar um fluxo enxuto de informação, mantendo a leitura como procedimento de investigação. Nesse âmbito, foram analisadas as principais publicações nacionais e internacionais relativas ao lean thinking - citadas em teses, dissertações, artigos e livros consagrados sobre o tema - e à qualidade da informação. A literatura de referência em lean mostrou ignorar o que concerne à informação e sua gestão em quaisquer ambientes, atendo-se a aspectos produtivos, como sequência de atividades e distribuição de materiais. Já a literatura da Ciência da Informação, pouco busca relações com a engenharia, no que tange a seus objetos de estudo.

A inexistência de aspectos em comum, testados cientificamente entre ambas as áreas, reforçou a necessidade de estudos a respeito da avaliação de fluxos informacionais e sua relação com conceitos como de valor, fluxo, cadeia de valor, puxar, perfeição, oriundos da produção e considerados de uso potencial pelos profissionais da informação.

Extraiu-se, então, da literatura reunida para a pesquisa, conceitos e características lean, a serem correlacionadas aos critérios de qualidade informacional (Quadro 2), nas etapas seguintes dos procedimentos. Partiu-se para a categorização das características selecionadas, como operacionais (atividades, sua sequência e sua realização), gerenciais 
(análise, planejamento, e tomada de decisão) ou ambos, conforme a pertinência de sua estrutura.

No passo seguinte, recortaram-se os principais elementos das teorias - lean thinking e qualidade da informação -, sendo estruturados, respectivamente, como linhas e colunas de um quadro. A leitura cruzada dos elementos permitiu a análise da compatibilidade entre os componentes de ambas as teorias, partindo da questão norteadora: "Quando se trata da característica $C$ da mentalidade enxuta, pode-se também estar tratando do critério $Q$ de qualidade da informação considerada a definição deste último?".

A verificação da resposta culminou em somatório do número de critérios de qualidade informacional relacionados a cada característica lean, sendo aquelas com maior número de correlações com os referidos critérios, bases para o conceito de Fluxo Enxuto de Informação (FEI). Por fim, a referência das características quanto à operação e/ou ao gerenciamento de fluxo informacional permitiu a atribuição de um foco (gerencial, operacional, ou ambos) ao FEI.

\section{Fluxo enxuto de informação (FEI)}

As correlações entre critérios qualificadores de fluxos informacionais sob a ótica da Ciência da Informação e as 17 características inerentes à mentalidade enxuta, identificadas na literatura, são apresentados nos Quadros 3, 4 e 5. Os Quadros referem-se, respectivamente, às características relativas a atividades operacionais (5 de 17), gerenciais (7 de 17) e ambas simultaneamente (5 de 17).

A leitura dos Quadros demonstra as correlações identificadas durante a análise conceitual de ambas as vertentes teóricas, por exemplo, no Quadro 3: "o fluxo, de sua criação à entrega da informação ao usuário, é ou tem seu fluxo produtivo/de criação, representado visualmente, facilitando a efetiva observação das situações. Quando se trata desta característica sob a ótica da qualidade da informação, trata-se, também, de abrangência/escopo; acurácia/veracidade; confiabilidade; contextualização; pertinência / agregação de valor; aceitação; apresentação / mídia e detalhamento desse recurso".

Quadro 3 - Relação entre critérios de qualidade da informação e características Lean - operacionalização de fluxos de informação

\begin{tabular}{l|l|c}
\hline $\begin{array}{l}\text { O fluxo de criação à entrega da } \\
\text { informação ao usuário: }\end{array}$ & $\begin{array}{l}\text { Critérios de qualidade da } \\
\text { informação relacionados à } \\
\text { característica lean }\end{array}$ & $\begin{array}{c}\text { Total de } \\
\text { critérios } \\
\text { relacionados }\end{array}$ \\
\hline $\begin{array}{l}\text { É, ou tem seu fluxo produtivo/de criação, } \\
\text { representado visualmente, facilitando a } \\
\text { efetiva observação das situações }\end{array}$ & $\begin{array}{l}\text { Abrangência / Escopo; Acurácia / } \\
\text { Veracidade; Confiabilidade; } \\
\text { Contextualização; Pertinência / } \\
\text { Agregação de valor; Aceitação } \\
\text { Apresentação / Mídia; Detalhamento }\end{array}$ & 8 \\
\hline Obedece à comunicação clara & $\begin{array}{l}\text { Identidade; Apresentação / Mídia; } \\
\text { Clareza; Detalhamento; Concisão; } \\
\text { Ordem }\end{array}$ & 6 \\
\hline
\end{tabular}




\begin{tabular}{l|l|c}
\hline $\begin{array}{l}\text { Conta com um processo e método(s) } \\
\text { definido(s) e padronizado(s) }\end{array}$ & $\begin{array}{l}\text { Confiabilidade; Identidade; } \\
\text { Apresentação / Mídia; Clareza; Ordem }\end{array}$ & 5 \\
\hline $\begin{array}{l}\text { Sequencia, de maneira otimizada, as } \\
\text { atividades de geração de valor }\end{array}$ & $\begin{array}{l}\text { Identidade; Apresentação / Mídia; } \\
\text { Clareza; Ordem }\end{array}$ & 4 \\
\hline $\begin{array}{l}\text { É sistematizado de modo a permitir a } \\
\text { análise distinta dos fluxos de produto e de } \\
\text { trabalho }\end{array}$ & Ordem & 1 \\
\hline
\end{tabular}

Fonte: As Autoras (2010)

O Quadro 4, por sua vez, contém as correlações entre as características da mentalidade enxuta identificadas na literatura e classificadas como relativas à gestão do fluxo de informação:

Quadro 4 - Relação entre critérios de qualidade da informação e características Lean - gestão do fluxo de informação

\section{O fluxo de criação à entrega da informação ao usuário:}

Especifica o valor, e onde é gerado, em relação ao produto, suas funções, preço e interesse do(s) cliente(s)
Incentiva uma visão que extrapola os limites dos processos organizacionais,

diferenciando ciclos interno e externo

\section{Critérios de qualidade da informação relacionados à característica lean}

Abrangência / Escopo; Acurácia /

Veracidade; Confiabilidade; Clareza;

Confidencialidade / Privacidade;

Disponibilidade / Prontidão; Existência;

Precisão; Contextualização; Ineditismo

/ Raridade; Relevância; Audiência;

Originalidade; Pertinência / Agregação

de valor; Aceitação; Integridade

Abrangência / Escopo; Atualidade /

Período / Temporalidade;

Confiabilidade; Contextualização;

Identidade; Pertinência / Agregação de

valor; Amplitude; Apresentação /

Mídia; Clareza; Detalhamento; Ordem

Pertinência / Agregação de valor;

Apresentação / Mídia; Clareza;

Concisão; Detalhamento; Precisão;

Ordem; Relevância

oferecendo bases para implementação da

melhoria contínua

Atualidade / Período / Temporalidade;

Existência; Contextualização;

Pertinência / Agregação de valor;

Amplitude; Detalhamento; Relevância; Integridade

e o planejamento de seu estado futuro, visando à melhoria

Mantém a agregação de valor como uma constante, conduzindo suas atividades com crescente efetividade

Mantém as decisões a ele inerentes fundamentadas na experiência, evitando seu embasamento em opiniões e suposições

Abrange o fluxo de valor que acompanha cada ciclo de informação ao longo do processo

Fonte: As Autoras (2010).

O Quadro 5, enfim, apresenta as correlações teóricas entre características lean relativas tanto à gestão quanto à operacionalização do fluxo de informação e respectivos totais de critérios de qualidade relacionados:
Confiabilidade; Pertinência /

Agregação de valor; Audiência; Ordem

Acurácia / Veracidade; Aceitação;

Confiabilidade; Existência

Abrangência / Escopo; Identidade

2

4

4 critérios relacionados 16

10

8

8 
Quadro 5 - relação entre critérios de qualidade da informação e características Lean - gestão e operação de fluxo informacional

\begin{tabular}{|c|c|c|}
\hline $\begin{array}{l}\text { O fluxo de criação à entrega da } \\
\text { informação ao usuário: }\end{array}$ & $\begin{array}{l}\text { Critérios de qualidade da } \\
\text { informação relacionados à } \\
\text { característica lean }\end{array}$ & $\begin{array}{l}\text { Total de } \\
\text { critérios } \\
\text { relacionados }\end{array}$ \\
\hline $\begin{array}{l}\text { Aplica antídotos para o desperdício, } \\
\text { inclusive quanto a equipamentos e mídias, e } \\
\text { conta com meios para obter feedback } \\
\text { quanto às ações de conversão do } \\
\text { desperdício em valor }\end{array}$ & $\begin{array}{l}\text { Atualidade / Período / Temporalidade; } \\
\text { Disponibilidade / Prontidão; Existência; } \\
\text { Ineditismo / Raridade; Originalidade; } \\
\text { Pertinência / Agregação de valor; } \\
\text { Apresentação; Clareza; Precisão; } \\
\text { Concisão; Relevância; Detalhamento; } \\
\text { Ordem }\end{array}$ & 13 \\
\hline $\begin{array}{l}\text { É operacionalizado e gerido de maneira } \\
\text { confiável }\end{array}$ & $\begin{array}{l}\text { Acurácia / Veracidade; Confiabilidade; } \\
\text { Confidencialidade / Privacidade; } \\
\text { Existência; Identidade; Integridade }\end{array}$ & 6 \\
\hline $\begin{array}{l}\text { Permite a previsão de falhas e a } \\
\text { identificação da causa de problemas e } \\
\text { respectivas soluções na produção e/ou } \\
\text { gerenciamento }\end{array}$ & $\begin{array}{l}\text { Apresentação / Mídia; Clareza; } \\
\text { Concisão; Detalhamento; Precisão; } \\
\text { Ordem }\end{array}$ & 6 \\
\hline $\begin{array}{l}\text { E operacionalizado e gerido de maneira } \\
\text { transparente }\end{array}$ & $\begin{array}{l}\text { Acurácia / Veracidade; Integridade; } \\
\text { Confiabilidade; Confidencialidade / } \\
\text { Privacidade; Identidade }\end{array}$ & 5 \\
\hline $\begin{array}{l}\text { É gerenciado e executado de modo a } \\
\text { diminuir o trabalho empurrado (antecipado } \\
\text { indevidamente) e eliminar a estocagem }\end{array}$ & $\begin{array}{l}\text { Atualidade / Período / Temporalidade; } \\
\text { Disponibilidade / Prontidão }\end{array}$ & 2 \\
\hline
\end{tabular}

Fonte: As Autoras (2010).

A incidência das correlações demonstradas nos Quadros aponta que as áreas analisadas, durante a pesquisa, efetivamente têm aspectos de interseção, representando um campo potencial de estudos na Ciência da Informação, no sentido de eliminar fronteiras com novas áreas do conhecimento, por exemplo, a engenharia.

O número de correlações apresentadas em cada Quadro demonstra que as características do lean thinking entram em consonância com os critérios de qualidade da informação na seguinte ordem de quantificação de ocorrências quanto:

a) à clareza, ordem, apresentação/mídia e confiabilidade da informação (8 ocorrências no total), sendo apresentada ao cliente/usuário, desprovida de erros de comunicação ou formato e cujos problemas e respectivas causas têm a identificação facilitada. Destes critérios, somente a confiabilidade é relacionada em maioria a elementos de gestão do fluxo informacional, sendo os demais, prioritariamente relativos à operacionalização deste;

b) ao detalhamento, à pertinência/agregação de valor e à identidade da informação em fluxo (7 ocorrências), quando se trata de atender demandas de usuários em meio às atividades deste último. Destes critérios, somente a identidade tem reflexo principalmente na vertente operacional da relação 
entre lean e qualidade da informação, sendo os demais, relacionados em maioria à gestão de fluxos desse recurso;

c) à acurácia/veracidade e à existência da informação, no que tange à confiança por parte dos usuários em relação às atividades realizadas no fluxo informacional (5 ocorrências). Tais critérios referem-se essencialmente à gestão do fluxo informacional, da qual parte a definição do valor que o perpassa;

d) à abrangência/escopo, contextualização, relevância, concisão, atualidade/período/temporalidade, precisão e integridade da informação (4 ocorrências). Estas relações se referem à localização da informação em fluxo no tempo, contexto e valor necessários à eliminação de desperdícios em atividades da sequência. Priorizam elementos gerenciais, como diagnóstico, planejamento e avaliação do fluxo, frente às operações deste; e

e) à confidencialidade/privacidade, à disponibilidade/prontidão e à aceitação da informação por parte de seus interessados (3 ocorrências), à sua audiência, originalidade, ineditismo/raridade e amplitude (2 ocorrências). Somente a última sucede em igual frequência entre características concernentes à gerência e à operacionalização do FEI, tendo os demais critérios, maior incidência junto à primeira categoria.

As características lean ignoram o desempenho e a frequência de uso da informação nas relações estabelecidas pela pesquisa, elementos que dependem da utilização propriamente dita dessa - subsequente ao fluxo de informação em si.

Entre as correlações estabelecidas, 24 são elencadas na vertente operacional de características da mentalidade enxuta e, portanto, dos fluxos informacionais, 52 para a gerencial, e 32, para ambas simultaneamente. Logo, comparando-se os resultados da análise de cada categoria, verifica-se que os elementos contemplados na pesquisa priorizam a gestão do principal valor inerente ao objeto de estudo: a informação. Observa-se uma preocupação em diagnosticar seu estado, definir objetivos de sua existência, planejar ações para cumpri-los e monitorá-las.

As diferenças atribuídas a cada critério de qualidade da informação por parte da gestão e da operação dos fluxos, diante da somatória das correlações, denotam complementaridade entre ambas as vertentes. Surge, assim, o pressuposto de que o planejamento e a gestão dos referidos fluxos, quando em conformidade aos princípios lean, naturalmente impedem e/ou diminuem a incidência de desperdícios em fluxos informacionais.

Obedecendo a ambas as vertentes, os fluxos de informação atendem ao conceito oriundo desta pesquisa, que considera os 
componentes lean mais presentes nas correlações identificadas e respectivos critérios de qualidade informacional: representação visual e comunicação clara (concernentes a diagnóstico e monitoramento); métodos definidos e padronizados (denotando planejamento e padrão de produtos e processos); e remediação de desperdícios.

Portanto, um Fluxo Enxuto de Informação preza o diagnóstico, o planejamento e o monitoramento de seus componentes, a contínua melhoria, a eliminação do desperdício de recursos, mantendo a informação como principal valor, pertinente a demandas e contextos, clara, organizada, confiável, dotada de identidade, apresentada e detalhada de modo inteligível e cujas atividades relacionadas obedecem a um padrão.

Complementam o conceito as correlações identificadas na pesquisa com menor incidência, entre mentalidade enxuta e qualidade da informação, portanto:

a) permite a seus interessados compreender seu estado atual e planejar estados futuros, conforme mudanças inerentes ao valor esperado;

b) é gerido e executado de maneira transparente e fundamentada na experiência, garantindo a acurácia/veracidade da informação e, consequentemente, sua existência e contextualização;

c) define a abrangência ou o escopo e a concisão informacionais conforme a demanda, preocupando-se em garantir atualidade, precisão, relevância e integridade desse recurso diante das atividades que o envolvem;

d) apresenta, também, de maneira transparente, ações baseadas na confidencialidade/privacidade, originalidade e ineditismo da informação conforme seu grau de importância;

e) tem a informação disponível e pronta para uso a partir do estabelecimento da demanda, mantendo sua aceitação, audiência e evitando a estocagem; e

f) permite a compreensão da amplitude da informação em fluxo, ao distinguir fluxos de trabalho e de produto, bem como os atores internos e externos ao contexto que neles atuam.

Os fatores contemplados no conceito e nas características complementares do FEI se aplicam à informação em fluxo, a seu suporte, às tarefas realizadas em relação a ambos e a demais recursos envolvidos. Para que o FEI seja plenamente incorporado ao ambiente que o almeja é preciso, ainda, considerar aspectos contextuais, que determinam a adequação da cultura do ambiente a premissas lean de qualidade informacional:

a) estrutura de trabalho que integra colaboradores; 
b) administração horizontal do ambiente;

c) integração e padronização de expectativas, procedimentos, rituais, cargos, regulamentos e prioridades, quanto à necessidade de reforçar, guiar e orientar o melhor comportamento;

d) incentivo à disciplina;

e) capacidade de reação rápida contra negligência, irresponsabilidade e problemas relacionados à disciplina;

f) aproveitamento de oportunidades de aumentar o domínio sobre áreas de exercício, desde que com a devida qualificação; e

g) utilização de toda estrutura física e tecnológica.

O conceito, aqui proposto, é passível de aplicação, mediante o mapeamento de fluxos de informação em quaisquer ambientes, permitindo a verificação da expectativa de seus clientes e usuários e da forma pela qual são atendidas por meio do fluxo.

\section{Considerações finais}

Ambientes nos quais a informação flui têm, em meios para avaliar esse processo, instrumentos de definição de melhores práticas e oportunidades de incremento de suas atividades, inclusive quanto ao uso de sua equipe de colaboradores, de tempo, estruturais, financeiros. As Oportunidades de desenvolvimento nesses ambientes zelam pela qualidade do valor entregue a seus clientes e usuários, agregam a si mesmos o autoconhecimento, que habilita a utilizar a informação para desenvolver-se interna e externamente. Como decorrências, a propriedade e a agilidade na tomada de decisão; a inovação em processos, produtos e serviços e a competitividade em relação a concorrentes criam espaços de aprendizagem.

À medida que fluxos de informação são compreendidos e tornados enxutos, a adequação destes ao valor esperado por seus interessados viabiliza o planejamento da realidade de todos os componentes do ambiente em questão, de maneira integrada. Mudanças culturais estão intrínsecas a essa conjuntura e tornam-se eficazes, quando da aplicação de uma série de mecanismos para administrar informações, como o Gerenciamento Eletrônico de Documentos, políticas e sistemas aderentes às estratégias e estruturas de dados, bancos de dados e mecanismos de mineração, gestão de projetos e do próprio conhecimento inerente aos processos.

A pesquisa originou parâmetros qualificadores do objeto de estudo em quaisquer contextos, fundamentadas na literatura, sob o viés teórico, bem como a demonstração de que práticas da mentalidade enxuta se aplicam à Gestão e, mais especificamente, a fluxos da Informação. O 
caráter interdisciplinar da última área é, assim, reforçado e seu profissional passa a dispor de uma gama de conhecimentos que enriquecem sua atuação na resposta a demandas e solução de problemas. O estudo e a avaliação de fluxos podem ser realizados pelo profissional da informação, aplicando procedimentos idênticos aos aqui apresentados, conforme a necessidade do ambiente em que está inserido.

A principal contribuição científica da pesquisa é a base para novas discussões a respeito da avaliação de fluxos de informação, deficiente e divergente em termos de publicações e métodos.

\section{Referências}

ALTISSIMO, T. L. Cultura organizacional, fluxo de informações e gestão do conhecimento: um estudo de caso. 2009. 168f. Dissertação (Mestrado em Ciência da Informação) - Universidade Federal de Santa Catarina, Florianópolis, 2009. Disponível em: <http://biblioteca.universia.net/html_bura/ficha/params/id/45993130.ht $\mathrm{ml}>$. Acesso em: 30 abr. 2010.

BARRETO, A. A. Mudança estrutural no fluxo do conhecimento: a comunicação eletrônica. Ciência da Informação, Brasília, v. 27, n. 2, p. 122-127, maio/ago. $1998 . \quad$ Disponível em: <http://revista.ibict.br/index.php/ciinf/article/viewFile/340/301>. Acesso em: 30 abr. 2010.

BEAL, A. Gestão estratégica da informação: como transformar a informação e a tecnologia da informação em fatores de crescimento e de alto desempenho nas organizações. São Paulo: Atlas, 2008.

CANOVA, F.; PICCHI, F. A. A aplicação da mentalidade enxuta no fluxo de informações de uma indústria de pré-fabricados de concreto. In: SIMPÓSIO BRASILEIRO DE GESTÃO E ECONOMIA DA CONSTRUÇÃO, 6., 2009, São Paulo. Anais... São Paulo: UFSCAR, 2009.

FARIAS, G. B. de. O bibliotecário - gestor da informação: representações do segmento imobiliário sobre competências. 2007. 190f. Dissertação (Mestrado em Ciência da Informação) - Universidade Federal de Santa Catarina, Florianópolis, 2007. Disponível em: <http://www.cin.ufsc.br/pgcin/GabrielaFarias.pdf>. Acesso em: 30 abr. 2010.

FREIRE, I. M. Barreiras na comunicação da informação. In: STAREC, C. et al. (Org.) Gestão estratégica da informação e inteligência competitiva. São Paulo: Saraiva, 2006. p. 33-46.

GIL, A. C. Métodos e técnicas de pesquisa social. 6. ed. São Paulo: Atlas, 2009.

HICKS, B. J. Lean information management: understanding and eliminating waste. International journal of information management, $\mathrm{v}$. 27, p. 233-249, 2007. Disponível em: <http://www.sciencedirect.com/science?_ob=ArticleURL\&_udi=B6VB4- 
4NP3P7S-

$1 \& \_$user $=10 \& \_r d o c=1 \& \_f m t=\& \_$orig $=$search \&_sort $=d \& \_$docanchor $=$\&view 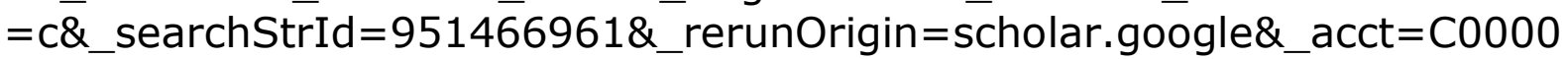 $50221 \&$ \&version $=1 \&$ _urlVersion $=0 \&$ _userid $=10 \& \mathrm{md} 5=9$ ae $95 \mathrm{fd} 8 \mathrm{a} 45 \mathrm{a} 27 \mathrm{f0}$ 06ce96d3b7579942>. Acesso em: 29 jun. 2009.

JACOSKI, C. A. Peculiaridades do fluxo de informações em pequenos escritórios de projeto de edificações. In: WORKSHOP BRASILEIRO DE GESTÃO DO PROCESSO DE PROJETO, 5., 2005, Florianópolis. Anais... Florianópolis: UFSC, 2005. Disponível em: <http://www.infohab.org.br>. Acesso em: 30 abr. 2010.

JAMIL, G. L. Repensando a TI na empresa moderna. Rio de Janeiro: Axcel Books, 2001.

LE COADIC, Y.-F. A ciência da informacão. Braília: Briquet de Lemos Livros, 1996 apud ALTISSIMO, T. L. Cultura organizacional, fluxo de informações e gestão do conhecimento: um estudo de caso. 2009. 168f. Dissertação (Mestrado em Ciência da Informação) - Universidade Federal de Santa Catarina, Florianópolis, 2009. Disponível em: <http://biblioteca.universia.net/html_bura/ficha/params/id/45993130.ht ml>. Acesso em: 30 abr. 2010.

LIKER, J. K. O modelo Toyota: 14 princípios de gestão do maior fabricante do mundo. Porto Alegre: Bookman, 2005.

MACHADO, M. C.; TOLEDO, N. N. Gestão do processo de desenvolvimento de produtos: uma abordagem baseada na criação de valor. São Paulo: Atlas, 2008.

MATTOS, A. N. de. Informação é prata compreensão é ouro: um guia para todos sobre como produzir e consumir informação na era da compreensão. Licença Creative Commons. 2010. Disponível em: <http://www.scribd.com/full/15933163?access_key=key-

4tikpnkunfdql9f3zqi>. Acesso em: 09 jun. 2010.

MCGEE, J. V.; PRUSAK, L. Gerenciamento estratégico da informação: aumente a competitividade e a eficiência de sua empresa utilizando a informação como uma ferramenta estratégica. 12. ed. Rio de Janeiro: Campus, 1994. 
OLIVEIRA, D. P. R. de. Sistemas, organização e métodos: uma abordagem gerencial. 13. ed. São Paulo: Atlas, 2002.

PICCHI, F. Lean thinking (mentalidade enxuta) aplicada à construção. In: SIMPÓSIO BRASILEIRO DE GESTÃO DA QUALIDADE, 2., 2001, Fortaleza. Anais... Fortaleza: Editoração Eletrônica Nordeste, 2001. CD-Rom.

ROCHA, F. E. M. da et al. Logística e lógica na construção lean. Fortaleza: Fibra Construções, 2004.

ROEDEL, D. Estratégia e inteligência competitiva. In: STAREC, C.; GOMES, E. B. P.; CHAVES, J. B. L. (Orgs.). Gestão estratégica da informação e inteligência competitiva. São Paulo: Saraiva, 2006. p. 67-86.

SANT'ANA, R. C. G.; SANTOS, P. L. V. A. C. Transferência de informação: análise de fatores para identificação do valor de unidades de conhecimento registrado. In: VIDOTTI, S. A. B. G. Tecnologia e conteúdos informacionais. São Paulo: Polis, 2004. p. 53-76.

SILVA, W. D. F. da. Introdução à gestão da informação. Campinas: Alínea, 2003.

SORDI, J. O. de. Administração da informação: fundamentos e práticas para uma nova gestão do conhecimento. São Paulo: Saraiva, 2008.

VAITSMAN, H. S. Inteligência empresarial: atacando e defendendo. Rio de Janeiro: Interciência, 2001.

WOMACK, J. P.; JONES, D. T. Lean thinking: banish waste and create wealth in your corporation. New York: Free press, 2003.

WURMAN, R. S. Ansiedade de informação: como transformar informação em compreensão. 5. ed. São Paulo: Cultura, 2003. 